\title{
Bacterial community associated with bovine tripe sold in Mafikeng Municipality, South Africa
}

\author{
Ndeddy Aka R. J. and Babalola Olubukola O.* \\ Department of Biological Sciences, Faculty of Agriculture, Science and Technology, North-West University, Mafikeng \\ Campus, Private Bag X2046, Mmabatho 2735, South Africa. \\ Accepted 19 May, 2011
}

\begin{abstract}
Enterobacteriaceae were isolated from tripe purchased from five butcher shops within the Mafikeng Municipality. Samples were subjected to bacteriological examination using standard methods. Mean counts $\left(\log _{10} \mathrm{cfu} / \mathrm{g}\right)$ obtained from bleached and unbleached tripe samples for aerobic plate counts $(5.62$ and 7.00), Enterobacteriaceae (4.09 and 4.61), Pseudomonas (4.20 and 4.57), lactic acid bacteria (2.15 and 2.35) and Micrococci/Staphylococci (3.82 and 5.61) were noted. Enterobacteriaceae on Violet Red Bile Agar were identified as; Enterobacter spp., Escherichia spp., Klebsiella spp., Serratia spp., Providencia stuartii (0.85\%), Hafnia alvei (7.63\%), Citrobacter spp., Salmonella arizonae (3.39\%), Erwinia spp. (0.85\%), Moellerella wisconsensis (3.39\%), Pantoea spp. (0.85\%), and Yersinia kristensii (0.85\%). A large percentage of Enterobacteriaceae (98.48\%) strains tested against nine antibiotics showed resistance to one or more. Some species from the genera Serratia, Enterobacter and Escherichia coli were resistant to seven out of the nine antibiotics. Highest resistance patterns were observed against nalidixic acid (96.4\%) and ampicillin (75\%). All isolates were susceptible to gentamicin and ciprofloxacin. Inadequate processing of bovine tripe sold at some butcher shops in Mafikeng poses a potential health risk to consumers due to their poor bacteriological quality and high frequency of antibiotic resistant agents. Resistant strains can be passed to the human population via consumption of such products.
\end{abstract}

Key words: Enterobacteriaceae, bacteriological quality, tripe, bleached, unbleached, antibiotic resistance.

\section{INTRODUCTION}

Tripe is an edible offal obtained from the first two chambers of a cattle's stomach: the rumen and the reticulum. It is a common and inexpensive product of high nutritional value with a distinguished taste. It is used to prepare stew. Such stew is eaten with pap (maize meal). There are two common and distinct grades of bovine tripe sold at most butcher outlets in Mafikeng in the North West Province of South Africa: bleached and unbleached tripe. Each of these products corresponds to a peculiar standard of sanitary quality that is based mainly on the processing technique employed during preparation. Tripe production generally involves four main steps which include disembowelment in which the stomach of a slaughtered cow is excised and its contents emptied;

\footnotetext{
${ }^{*}$ Corresponding author. E-mail: olubukola.babalola@nwu.ac.za. Tel: +27183892568. Fax: +27183892134
}

selected portions of the stomach wall are washed with water and may be treated with chemicals (for example, diactolate) to get rid of the odours and characteristic greenish colour. The cleaned stomach is then scalded and trimmed into several tripe pieces which are rinsed and packaged (Bensink et al., 2002). During this decontamination process, however, prior to packaging, the tripe may be held at temperatures that favour the growth and multiplication of contaminating bacteria. The growth of such undesired organisms which may include spoilage and pathogenic bacteria may be hazardous to consumers. Spoilage organisms are well known to reduce the shelf life of a food product causing it to lose its market value consequently causing economic loss to suppliers.

The Enterobacteriaceae family is one of the main bacterial groups implicated in the contamination of bovine tripe. Their presence in a food is an indication of improper hygienic measures during the entire sequence of processing (Gill and Landers, 2004) and inappropriate 
food storage. Within this group are found a wide range of Gram-negative bacilli of clinical significance. Many species of bacteria which are frequently encountered in hospital settings are found in this family and prominent members include Shigella spp., Yersinia spp., Salmonella spp. and Escherichia coli (Kornacki and Johnson, 2001; Miranda et al., 2008). These bacteria are causative agents of many food borne infections in humans and this includes diarrhoeal diseases, urinary tract infections, to more severe diseases such as respiratory tract infections and plague (Seral et al., 2002).

Other important members of the family Enterobacteriaceae belong to the genera Hafnia, Rahnella, Ewingella, Enterobacter and Serratia spp. These organisms have a striking ability to grow in a food product even at low temperatures. They are also capable of producing proteolytic and lipolytic enzymes (Losantos et al., 2000) that have negative effects on the organoleptic properties of meat and other food products. The mode of action of these enzymes involves rapid degradation of structural components in a food with subsequent production of foul odours generally making the food unacceptable to the consumer and also reducing its marketing range (Brightwell et al., 2007).

The development of antibiotic resistance among bacteria presents a serious health problem as resistant pathogens can be transferred to the human population when food contaminated by such undesirable organisms is consumed (Schwarz and Chaslus-Dancla, 2001; van den Bogaard and Stobberingh, 2000). The treatment of infections caused by drug resistant pathogenic bacteria is generally difficult and much more expensive especially amongst the elderly, infants and immuno-comprised people (Holmberg et al., 1984). In South Africa and other developing countries, food-borne diseases cause psychological suffering and loss of productivity. This problem could be further aggravated by an increasing resistance to antibiotics in many Enterobacteriaceae spp. which may cause infections in humans upon consumption of contaminated food leading to prolonged illnesses that may ultimately end in treatment failure. Moreover, some members of the Enterobacteriaceae family have the potential to cause spoilage. This results in short shelf life of tripe and may cause economic loss to suppliers.

The ruminant stomach is divided into four gastric compartments: rumen, reticulum, omasum and abomasum. These subdivisions act as fermentation vessels particularly for the degradation of cellulose (Teixeira et al., 2009). Microbiological examination has been used constantly to make sure that beef products entering the food chain do not contain bacteria that pose a health risk to the consumers. During the evisceration of the stomach of a slaughtered cow, bacterial contamination of tripe, especially by enteric bacteria is inescapable through direct contact with faecal material. Cross-contamination by numerous bacteria species may also happen as a result of improperly washed processing equipment and poor personnel hygiene. A number of important bacteria groups which have often been isolated from many meat products have also been found in tripe. These include Enterococcus, Staphylococcus, Pseudomonas, Corynebacterium, Campylobacter, Bacillus and Clostridium spp., Escherichia coli, Salmonella and many other members of the Enterobacteriaceae family (Bensink et al., 2002).

A biological indicator is a microorganism or group of microorganisms which are used as a tool during food analysis to gain insight about the level of contamination that may arise as a result processing and storage. They provide information about the safety of a product (Brown et al., 2000; Ingham et al., 2000; Moore and Griffith, 2002). Researchers have often considered the direct examination of food products for pathogenic bacteria as impractical. This is partly because the amount of pathogens present in a food can be so small that they may not be detected. This problem is compounded by sampling errors and lengthy recovery time period. However, the occurrence of indicator bacteria on a food product does not necessarily mean that the food certainly contains pathogens but rather it indicates the possible presence of food poisoning bacteria.

The objectives of the present study were: (1) to assess the microbiological profile of fresh beef tripe sold in five butcher shops in Mafikeng (South Africa); (2) to characterize isolates of Enterobacteriaceae from beef tripe and thereby identify them at genus and species level in order to ascertain which strains are potentially responsible for contamination and spoilage of tripe and; (3) to determine the antibiotic susceptibility of the Enterobacteriaceae strains obtained.

\section{MATERIALS AND METHODS}

\section{Sample collection and preparation}

Twenty two samples of bovine tripe were purchased from each of five butcher shops in Mafikeng, South Africa. Each establishment was visited on two occasions. Total number of samples consisted of eleven samples each of bleached and unbleached tripe. Each sample was placed in a separate sterile plastic bag and placed on ice in a cooler box which was immediately transported to the laboratory. Upon arrival at the microbiology laboratory, samples were held at $5^{\circ} \mathrm{C}$, examined and analyzed within $2 \mathrm{~h}$ from the time of purchase.

\section{Enumeration and isolation of bacteria}

$25 \mathrm{~g}$ of each sample was weighed aseptically and placed in a sterile masticator bag and homogenised with $225 \mathrm{ml}$ of buffered peptone water (Merck, Darmstadt) for 2 min in a homogeniser ( $\mathrm{T}-18$ basic ULTRA-TURRAX). Serial dilutions up to $10^{-9}$ were prepared using 9 $\mathrm{ml}$ aliquots of the same diluent. Dilutions were done with an automatic pipette (100 to $200 \mathrm{ml}$ ). The aerobic plate count was determined by spread plating $100 \mu \mathrm{l}$ of the appropriate dilutions $\left(10^{-}\right.$ 1 to $10^{-9}$ ) onto a Plate count agar (PCA). Plates were incubated aerobically at $35^{\circ} \mathrm{C}$ for 48 to $72 \mathrm{~h}$ and plates containing between 30 and 300 colonies were counted. Average counts were recorded as $\log _{10}$ colony forming unit (CFU) per gram. 
Table 1. Mean counts of bacteria $\left(\log _{10} \mathrm{Cfu} / \mathrm{g}\right)$ from bleached and unbleached tripe samples.

\begin{tabular}{lccccccc}
\hline Tripe treatment & Premises code & No. of samples & APC & ENB & PSE & LAB & Micro/Staph \\
\hline Bleached & BS-1 & 2 & 5.69 & 3.65 & 4.01 & 2.60 & 3.16 \\
& BS-2 & 2 & 5.27 & 3.88 & 4.36 & 1.07 & 4.22 \\
& BS-3 & 2 & 5.94 & 4.42 & 3.81 & 2.43 & 4.05 \\
& BS-4 & 2 & 5.46 & 3.78 & 4.26 & 2.64 & 4.17 \\
Unbleached & BS-5 & 2 & 5.88 & 4.78 & 4.58 & 2.01 & 3.49 \\
& Total & 10 & 5.62 & 4.09 & 4.20 & 2.15 & 3.82 \\
& & & & & & & \\
& BS-1 & 2 & 7.68 & 5.25 & 5.72 & 3.96 & 5.27 \\
& BS-2 & 2 & 6.21 & 4.88 & 4.49 & 1.75 & 5.82 \\
& BS-3 & 2 & 6.97 & 3.94 & 3.63 & 1.16 & 5.11 \\
& BS-4 & 2 & 8.44 & 4.64 & 5.72 & 2.86 & 6.08 \\
& BS-5 & 2 & 5.72 & 4.32 & 4.01 & 2.04 & 5.79 \\
\hline
\end{tabular}

$\mathrm{ENB}=$ Enterobacteriaceae, $\mathrm{APC}=$ Aerobic plate counts, $\mathrm{PSE}=$ Pseudomonas, Micro $=$ Micrococcus, Staph $=$ Staphylococcus, $\mathrm{LAB}=\mathrm{lactic}$ acid bacteria, BS= butcher shop.

The prevalence of Pseudomonas spp. was determined by spread plating $100 \mu \mathrm{l}$ portions of the appropriate dilutions unto Pseudomonas agar supplemented with cemetridine fucidine cephaloridine (CFC) incubated at $35^{\circ} \mathrm{C}$ for $48 \mathrm{~h}$. Lactic acid bacteria (LAB) were enumerated by plating $100 \mu$ on de Man Rogosa Sharpe agar (MRS) overlaid with $5 \mathrm{ml}$ of the same medium and incubated anaerobically at $30^{\circ} \mathrm{C}$ for $72 \mathrm{~h}$ and Staphylococci and Micrococci spp. on mannitol salt agar at $37^{\circ} \mathrm{C}$ for $72 \mathrm{~h}$. Enumeration of Enterobacteriacae was performed by spread plating $100 \mu \mathrm{l}$ portions of appropriate dilutions onto Violet Red Bile glucose agar which was incubated at $37^{\circ} \mathrm{C}$ for $24 \mathrm{~h}$.

\section{Characterization and identification of Enterobacteriaceae}

Typical colonies (pink red to purple with yellow zones) were considered as Enterobacteriaceae and counted. Counts were expressed as $\log _{10} \mathrm{CFU} / \mathrm{g}$. Up to 12 colonies (red to purple with yellow zones) on Violet Red Bile Agar with glucose (VRBG) plates were selected at random and streaked twice on nutrient agar plates which were incubated at 35 to $37^{\circ} \mathrm{C}$ for $24 \mathrm{~h}$ in order to obtain pure cultures for subsequent identification. Each isolate was characterized by testing for their Gram reaction and were examined for cellular morphology using a light microscope. Complementarily, motility, catalase, and oxidase test were performed to characterize the colonies at the bacterial group level. Presumptive Enterobacteriaceae isolates were then identified to genus and species by the Analytical Profile Index (API) 20E System (Biomerieux, France).

\section{Antibiotic susceptibility test (AST)}

This test was performed by using the disk diffusion method on Mueller-Hinton agar plates. A lawn of the diluted bacteria was spread in Muller Hinton plates with a cotton swab, then the antibiotic disks were dispensed into each plate with a disk dispenser and the plates were incubated at $35^{\circ} \mathrm{C}$ for $24 \mathrm{~h}$. After incubation, zones of inhibition around each disk were measured $(\mathrm{mm})$ and recorded. Isolates were classified as susceptible, intermediate and resistant strains according to Clinical and Laboratory Standards Institute' Guidelines. Resistance of an isolate to at least 2 classes of antibiotics was considered as multiple antibiotic resistances (Refika and Marlyn, 2001). The antibiotic disks tested and their concentrations are: Chloramphenicol $(30 \mu \mathrm{g})$, Ciprofloxacin $(5 \mu \mathrm{g})$, Tetracycline $(30 \mu \mathrm{g})$ Cefuroxime $(30 \mu \mathrm{g})$, Trimethoprim-Sulfamethoxazole $(25 \mu \mathrm{g})$, Ampicillin $(10 \mu \mathrm{g})$, Gentamicin $(10 \mu \mathrm{g})$, Nalidixic Acid $(30 \mu \mathrm{g})$, Ceftazidime $(10 \mu \mathrm{g})$

\section{RESULTS AND DISCUSSION}

The stomach of a cow is home to millions of microbes and therefore contamination of tripe derived from the rumen and reticulum is difficult to avoid especially during the evisceration process (Bensink et al., 2002). In the present study, the microbiological profile of both bleached and unbleached tripe sold at selected butcher shops in Mafikeng was evaluated. A total of 22 samples of tripe (bleached and unbleached) were collected and analyzed. This study was undertaken for a time period of eight weeks, during the summer. Table 1 presents the counts for the Aerobic Plate Counts (APC), Enterococci spp., Micrococcus/Staphylococcus spp., lactic acid bacteria and Enterobacteriaceae in log CFU/g.

\section{Counts of the different bacterial groups}

The log means for the APC were high, 5.62 and 7.00 for bleached and unbleached tripe, respectively (Table 1). This difference in APC between both grades of tripe could be due to the method of processing employed. The high APC particularly from unbleached tripe was possibly as a result of inadequate washing, high ambient temperature in Mafikeng to support bacterial growth and possible handling contamination.

Enterobacteriaceae mean counts ranges between were $\log _{10} 4.09$ and 4.61 . These counts were much similar to 
those in the literature (Crowley et al., 2005) on the investigation on beef products from retail outlets in the Republic of Ireland. Crowley et al. (2005) obtained mean counts in a range of 2.20 to $4.64 \log _{10} \mathrm{Cfu} / \mathrm{g}$ which indicated inadequate processing, handling and storage of the products. Also, such high counts could be potentially responsible for the short shelf life of tripe.

The occurrence of Micrococcus and Staphylococcus was found at 3.82 for the bleached and 5.61 for the unbleached tripe. The presence of Staphylococci in such high numbers could be as a result of cross contamination particularly poor personal hygiene amongst the food handlers during slaughtering, dressing and evisceration or recontamination of the finished product through flies.

Lactic acid bacteria counts averaged 2.35 for bleached tripe and $2.15 \mathrm{Cfu} / \mathrm{g}$ for unbleached tripe. The average counts for LAB found on tripe samples were slightly higher than results obtained by Garcia et al. (2000) who reported counts of $2 \mathrm{log} \mathrm{Cfu} / \mathrm{g}$ in spoiled and unspoiled ham.

Finally, the mean log counts of Pseudomonas were 4.20 to 4.57. The isolation of Pseudomonas spp. is of high significance because this organism plays a substantial role as a pathogen and as an indicator of meat spoilage (Buys, 2000). Jeyasekaran et al. (2006) isolated and identified these organisms as good spoilage indicators and this is primarily because they are capable of growing on meat stored under aerobic conditions at low temperatures (Buys, 2000). The numbers observed in this survey may be as a result of dirty processing equipment and a lack of proper refrigeration at butcheries.

Generally, bacterial counts on unbleached tripe were significantly higher than those obtained from bleached tripe samples. This indicated that the bacteriological quality of tripe depends on the method of processing employed during production (Bensink et al., 2002).

\section{Identification of isolated Enterobacteriaceae}

The composition of Enterobacteriaceae microflora of tripe according to the API data showed values thus: Enterobacter cloacae (15.3\%), Escherichia coli (10.2\%), Klebsiella ornithinolytica (11.86\%), Klebsiella pneumoniae $(0.85 \%)$ Serratia liquefaciens $(11.86 \%) P$. stuartii $(0.85 \%)$, Klebsiella planticola $(0.85 \%)$, Serratia fonticola (0.69\%), Klebsiella terigena (0.85\%), Enterobacter amnigenus (4.27\%), Hafnia alvei (7.63\%), Citrobacter braakii (0.85\%), Enterobacter gergoviae (0.85\%), Salmonella arizonae (3.39\%), Serratia odorifera (5.93\%), Escherichia fergusonii (1.69\%), Erwinia spp $(0.85 \%)$, Moellerella wisconsensis (3.39\%), Pantoea spp. (0.85\%), Enterobacter aerogenes (2.54\%), Enterobacter sakazakii, Citrobacter freundii (0.85\%), Yersinia enterocolitica (1.69\%), Yersinia kristensii $(0.85 \%)$, and Klebsiella oxytoca (2.54\%).

Many of the identified species have been isolated from a wide variety of foods such as meat, chicken, cheese beef, pork and the gastrointestinal tracts of mammals including in aquatic environments and hospitals (Adesiyun et al., 2006; Brightwell et al., 2007; Dromigny et al., 2003). Besides, E. sakazakii, K. oxytoca and Pseudomonas have been isolated from soil (Babalola et al., 2004). All isolates used o-nitrophenyl- $\beta$-galactopyranoside which gave evidence about the presence of the $\beta$-galactosidase enzyme. Few strains reduced nitrates, whereas all the species produced acid from glucose. The fermentation patterns of all isolates together with percentages of occurrence of species of the genera Enterobacter, Citrobacter, Escherichia, Klebsiella, Serratia and Salmonella in tripe samples was of great significance due to their spoilage and pathogenic potentials (Brightwell et al., 2007; Ridell and Korkeala, 1997). Hafnia alvei, Enterobacter amnigenus and Serratia liquefaciens have been reported to be capable of growth at low temperatures and have been shown to be a potential cause of food spoilage and opportunistic infections (Tallgren et al., 1999; Tamagnini et al., 2008). Contamination of tripe by these organisms could without question yield significant economical losses.

K. pneumoniae and K. oxytoca are also opportunistic pathogens that have been linked over the years as the main cause of diseases in humans such as septicaemia, pneumonia, urinary tract infections and soft tissue infections (Cai et al., 2008; Kovtunovych et al., 2003).

E. sakazakii, E. cloacae and $C$. freundii are associated with illnesses such as necrotizing enterocolitis, diarrhoea, meningitis, urinary tract infections, intra-abdominal and ophthalmic infections and septicaemia (Lai, 2001; Van Acker et al., 2001; Yu et al., 2000).

The presence of these bacteria groups, especially $E$. coli, indicated contamination with faecal material and environmental pollution and these supported the findings of Herrera et al. (2006) who isolated similar organisms from fish and fish products.

\section{Antibiotic resistance levels}

Antibiotic resistance is a global problem and has always been a major concern for bacterial infections in clinical environments. Since drug resistance in zoonotic bacteria has limited treatment options against bacterial infections or diseases in humans, antibiotic resistance in food-borne pathogens has become a significant health issue. The frequencies of resistance of 87 Enterobacteriaceae strains are presented in Table 2. As shown in the table, majority of the isolates were resistant to NA acid, $96.4 \%$ and AMP, $75 \%$. All isolates were susceptible to GEN and CIP whereas SXT, CHL and CXM were consistently the most active agents against most of the isolates, 60.2, 86 and $83.1 \%$, respectively. The resistance frequencies presented in this study for AMP were much higher than those published by Miranda et al. (2008) who found 21.7, 
Table 2. Susceptibility levels of the Enterobacteriaceae isolates to the antimicrobial agents tested.

\begin{tabular}{lccc}
\hline \multirow{2}{*}{ Antibiotic } & \multicolumn{3}{c}{ Susceptibility (\%) } \\
\cline { 2 - 4 } & Resistant & Intermediate & Susceptible \\
\hline Nalidixic acid & 96.4 & - & 3.6 \\
Gentamicin & - & - & 100 \\
Ciproflaxin & - & - & 100 \\
Ampicilin & 75 & 12 & 13 \\
Cefuroxine & 16.9 & - & 83.1 \\
Tetracycline & 41 & 22 & 37 \\
Chloramphenicol & 4 & 10 & 86 \\
Ceftazidime & 24.1 & 9.6 & 66.3 \\
Trimethoprimsulfamethoxazole & 39.8 & - & 60.2 \\
\hline
\end{tabular}

Table 3. Susceptibility pattern of the Enterobacteriaceae isolates to the antimicrobial agents tested.

\begin{tabular}{lcccccccccc}
\hline \multirow{2}{*}{ Isolate } & \multirow{2}{*}{ No. tested } & \multicolumn{8}{c}{ Percentage resistant } \\
\cline { 3 - 11 } & & NA & GEN & CIP & AMP & CTM & TET & CHL & SXT & CXM \\
\hline Escherichia coli & 12 & 25 & - & - & 75 & 41.7 & 8.3 & 16.6 & 33.3 & 8.3 \\
Hafnia spp. & 7 & - & - & - & 71.4 & 57.1 & 14.3 & 28.6 & 14.3 & 28.5 \\
Klebsiella spp. & 15 & 13.3 & - & - & 60 & 73.3 & - & - & 13.3 & 26.7 \\
Citrobacter spp. & 2 & - & - & - & 100 & - & 100 & 50 & 100 & - \\
Enterobacter spp. & 29 & 20.5 & - & - & 41.4 & 62.1 & 58.6 & 17.2 & 27.6 & 58.6 \\
Serratia spp. & 18 & 44.4 & - & - & 27.8 & 33.3 & 55.6 & 66.7 & 16.7 & 83.3 \\
Total & 83 & & - & - & & & & & & \\
\hline
\end{tabular}

AMP, ampicillin; TET, tetracycline; NA, nalidixic acid; CXM, cefuroxime; SXT, trimethoprim-sulfamethoxazole; CTM Ceftazidime; GEN, gentamicin; CIP, ciprofloxacin; CHL, chloramphenicol.

35 and $33.3 \%$ AMP resistance among Enterobacteriaceae isolates from organic chicken, conventional chicken and turkey, respectively. In the same study, only $61 \%$ of isolates were susceptible to CIP whereas in our study all isolates where sensitive.

The incidence of TET resistance was $41 \%$. Tetracycline resistance mainly occurs when an organism acquires tetracycline resistance (Roberts, 1996) determinants such as efflux proteins and enzymatic alterations. Resistance to SXT (39.8\%) is probably as a result of alterations in chromosomal genes (Huovinen et al., 1985). The high rate of resistance to quinolones according to Charles (2006) is primarily caused by gene mutation of target enzymes. Most organisms were resistant to at least three antibiotics but many $E$. coli and Serratia spp. showed resistance to 7 out of 9 antibiotics tested while only five Enterobacter isolates were susceptible to all antibiotics (Table 3 ).

Citrobacter spp. exhibited high rates of susceptibility to most agents except for TET, CHL and SXT. Among E. coli isolates, $75 \%$ were susceptible to nalidixic acid, $25 \%$ to ampicillin and $58.3 \%$ to CTM, $83.4 \%$ to $\mathrm{CHL}, 66.7 \%$ to SXT and $91.7 \%$ to CXM. Only $28.6 \%$ of Hafnia spp. were sensitive to AMP while $42.9 \%$ were sensitive to CTM,
$85.7 \%$ to tetracycline, $71.4 \%$ to $\mathrm{CHL}, 85.7 \%$ to SXT and $71.5 \%$ to CXM. For Enterobacter isolates, the susceptible percentages of the the six agents were 58.6, 37.9, $41.4,82.2,72.4$ and $41.4 \%$, respectively, with $79.5 \%$ sensitivity to NA. Klebsiella spp. were more sensitive to NA and SXT (86.3\%) than any other isolate. $40 \%$ was sensitive to AMP, $73.3 \%$ to CXM and only $26.7 \%$ to CTM. The antibiotic resistance patterns of different genera of Enterobacteriaceae isolated from tripe samples are shown in Table 3.

Resistance to multiple antibiotics by Enterobacteriacae spp. have also been reported by other researchers (Dromigny et al., 2003; Sarter et al., 2007) and according to Baquero et al. (1998), this may be primarily due to the ability of the bacteria to adapt and survive in a constantly changing antibiotic environment. This gives rise to a phenomenon called selective pressure. It is well known that Gram-negative bacteria posses efflux pumps which aid them to resist many antibiotics by actively pumping out the drug from the cell before it reaches its target (Okusu et al., 1996).

The successful completion of this task will aid this research toward its long-run objective which is intended to increase the body of scientific knowledge regarding the 
safety and quality of retail beef tripe. This information will help expand the body of scientific knowledge regarding microbial physiology, which may inform us about microbial physiology as well as the biochemical characteristics of bacteria found in the Enterobacteriaceae family which will further help to evaluate possible risks involved with the consumption of beef tripe.

\section{Conclusion}

The findings from this study show that the bacteriological quality of tripe varies and depends on the technique used in processing. Secondly, post process contamination may occur during evisceration of the stomach, or as a result of the hygiene conditions in the butchery. The temperature and general conditions of storage play important roles in the hygiene conditions in the butchery. Bacteria counts together with API data obtained, indicated relatively high levels of contamination of tripe and different species of pathogenic Enterobacteriaceae most of which have been described to cause serious infections and diseases in humans. Furthermore, many isolates recovered from tripe samples demonstrated resistance to commonly used antibiotics with some being resistant to 7 out of the 9 antibiotics tested. All these information make bovine tripe a concern for consumers, suppliers as well as an issue for public health especially if it is not properly cooked and consumed as resistant pathogens can be passed into the human population. For this reason, effective programs to prevent contamination and growth of these undesired organisms should be established in the meat industry to control the incidence of food contamination with resistant pathogens. Lastly, efforts should be made to inform the public on good sanitary practices in handling tripe and consumption of only properly tripe product.

\section{ACKNOWLEDGEMENTS}

We thank the Senior Technician, Ms. Huyser Rika, and Mr. J. Morapedi for laboratory assistance. We also thank anonymous reviewers for their valuable comments.

\section{REFERENCES}

Adesiyun A, Offiah N, Seepersadsingh N, Rodrigo S, Lashley V, Musai $L$ (2006). Frequency and antimicrobial resistance of enteric bacteria with spoilage potential isolated from table eggs. Food Res. Int., 39: 212-219.

Babalola OO, Sanni AI, Odhiambo GD (2004). Isolation of rhizobacteria associated with maize and assessment of their potential for use in Striga hermonthica (Del.) Benth. Suicidal germination. J. Trop. Microbiol., 3: 64-70.

Baquero F, Negri MC, Morosini MI, Blazquez J (1998). Antibioticselective environments. Clin. Infect. Dis., 27: S5-S11.

Bensink JC, Dobrenov B, Mulenga MP, Bensink ZS, McKee JJ (2002). The microbiological quality of beef tripe using different processing techniques. Meat Sci., 62: 85-92.

Brightwell G, Clemens R, Urlich S, Boerema J (2007). Possible involvement of psychrotolerant Enterobacteriaceae in blown pack spoilage of vacuum-packaged raw meats. Inter. J. Food Microbiol., 119: 334-339.

Brown MH, Gill CO, Hollingsworth J, Nickelson li R, Seward S, Sheridan JJ, Stevenson T, Sumner JL, Theno DM, Usborne WR, Zink D (2000). The role of microbiological testing in systems for assuring the safety of beef. Inter. J. Food Microbiol., 62: 7-16.

Buys EM (2000). Bacterial populations associated with bulk packaged beef supplemented with dietary vitamin E. Inter. J. Food Microbiol., 56: 239-244.

Cai J, Wang Z, Cai C, Zhou Y (2008). Characterization and identification of virulent Klebsiella oxytoca isolated from abalone (Haliotis diversicolor supertexta) postlarvae with mass mortality in Fujian, China. J. Inverteb. Pathol., 97: 70-75.

Charles RW (2006). Antimicrobial resistance: Mechanisms and strategies. Paediatric respiratory rev., 7: S128-S129.

Crowley H, Cagney C, Sheridan JJ, Anderson W, McDowell DA, Blair IS, Bishop RH, Duffy G (2005). Enterobacteriaceae in beef products from retail outlets in the Republic of Ireland and comparison of the presence and counts of $E$. coli $\mathrm{O} 157: \mathrm{H} 7$ in these products. Food Microbiol., 22: 409-414.

Dromigny JA, Ndoye B, Macondo EA, Nabeth P, Siby T, Perrier-GrosClaude JD (2003). Increasing prevalence of antimicrobial resistance among Enterobacteriaceae uropathogens in Dakar, Senegal: a multicenter study. Diagnostic Microbiol. Infect. Dis., 47: 595-600.

Garcia C, Martın A, Timon ML, Cordoba JJ (2000). Microbial populations and volatile compounds in the "bone taint" spoilage of dry-cured ham. Lett. Appl. Microbiol., 30: 61-66.

Gill CO, Landers C (2004). Proximate sources of bacteria on boneless loins prepared from routinely processed and detained carcasses at a pork packing plant. Int. J. Food Microbiol., 97: 171-178.

Herrera FC, Santos JA, Otero A, Garcia-Lopez ML (2006). Occurrence of foodborne pathogenic bacteria in retail prepackaged portions of marine fish in Spain. J. Appl. Microbiol., 100: 527-536.

Holmberg SD, Wells JG, Cohen ML (1984). Animal-to-man transmission of antimicrobial-resistant Salmonella: investigations of U.S. outbreaks, 1971-1983. Science, 225: 833-835.

Huovinen P, Renkonen O-V, Pulkkinen L, Sunila R, Gronroos P, Klossner ML, Virtanen S, Toivanen P (1985). Trimethoprim resistance of Escherichia coli in outpatients in Finland after ten years' use of plain trimethoprim. J. Antimicrobial Chemothe., 16: 435-441.

Ingham SC, Reyes JCN, Schoeller NP, Lang MM (2000). Potential use of presumptive enterococci and staphylococci as indicators of sanitary condition in plants making hard Italian-type cheese. J. Food Protect., 63: 1697-1701.

Jeyasekaran GJ, Ganesan P, Anandaraj R, Jeya Shakila R, Sukumar D (2006). Quantitative and qualitative studies on the bacteriological quality of Indian white shrimp (Penaeus indicus) stored in dry ice. Food Miocrobiol., 23: 526-533.

Kornacki JL, Johnson JL (eds). (2001). Enterobacteriaceae, coliforms, and Escherichia coli as quality and safety indicators. 4th ed. American Public Health Association: Washington, D.C.

Kovtunovych G, Lytvynenko T, Negrutska V, Lar O, Brisse $\mathrm{S}$, Kozyrovska N (2003). Identification of Klebsiella oxytoca using a specific PCR assay targeting the polygalacturonase pehX gene. Res. Microbiol., 154: 587-592.

Lai KK (2001). Enterobacter sakazakii infections among neonates, infants, children, and adults - Case reports and a review of the literature. Medicine, 80: 113-122.

Losantos A, Sanabria C, Cornejo I, Carrascosa AV (2000). Characterization of Enterobacteriaceae strains isolated from spoiled dry-cured hams. Food Microbiol., 17: 505-512.

Miranda JM, Guarddon M, Vázquez BI, Fente CA, Barros-Velázque ZJ, Cepeda A (2008). Antimicrobial resistance in Enterobacteriaceae strains isolated from organic chicken, conventional chicken and conventional turkey meat: A comparative survey. Food Control, 19:

412-416.

Moore G, Griffith C (2002). A comparison of surface sampling methods for detecting coliforms on food contact surfaces. Food Microbiol., 19: 65-73.

Okusu H, Ma D, Nikaido H (1996). AcrAB efflux pump plays a major role in the antibiotic resistance phenotype of Escherichia coli 
multiple-antibiotic-resistance (Mar) mutants. J. Bacteriol., 178: 306-308. Refika H, Marlyn SW (2001). Advanced cystic fibrosis lung disease in children. Current opinion in pulmonary medicine. Pulmonary Med., 7: 448-453.

Ridell J, Korkeala H (1997). Minimum growth temperatures of Hafnia alvei and other Enterobacteriaceae isolated from refrigerated meat determined with a temperature gradient incubator. Int. J. Food Microbiol., 35: 287-292.

Roberts MC (1996). Tetracycline resistance determinants: Mechanisms of action, regulation of expression, genetic mobility, and distribution. Fems Microbiol. Rev., 19: 1-24.

Sarter S, Hoang NK, Le Thanh H, Jerome L, Didier M (2007). Antibiotic resistance in Gram-negative bacteria isolated from farmed cattish. Food Control, 18: 1391-1396.

Schwarz S, Chaslus-Dancla E (2001). Use of antimicrobials in veterinary medicine and mechanisms of resistance. Vet. Res., 32: 201-225.

Seral C, Castillo FJ, Llorente MT, Varea M, Clavel A, Rubio MC, Gómez-Lus R (2002). The eaeA gene is not found in Hafnia alvei from patients with diarrhea in Aragón, Spain. Int. J. Microbiol., 4: 8182.

Tallgren $\mathrm{AH}$, Airaksinen $\mathrm{U}$, von Weissenberg $\mathrm{R}$, Ojamo $\mathrm{H}$, Kuusisto $\mathrm{J}$, Leisola M (1999). Exopolysaccharide-producing bacteria from sugar beets. Appl. Environ. Microbiol., 65: 862-864.
Tamagnini LM, de Sousa GB, Gonzalez RD, Budde CE (2008). Behavior of Enterobacter amnigenus and Salmonella typhimurium in Crottin goat's cheese: Influence of fluctuating storage temperature. Small Ruminant Res., 76: 177-182.

Teixeira AF, Kuhnel W, Vives P, Wedel T (2009). Functional morphology of unguiculiform papillae of the reticular groove in the ruminant stomach. Annal. Anatomy-Anatomischer Anzeiger, 191: 469-476.

Van Acker J, De Smet F, Muyldermans G, Bougatef A, Naessens A, Lauwers S (2001). Outbreak of necrotizing enterocolitis associated with Enterobacter sakazakii in powdered milk formula. J. Clin. Microbiol., 39: 293-297.

van den Bogaard AE, Stobberingh EE (2000). Epidemiology of resistance to antibiotics: Links between animals and humans. Int. J. Antimicrobial Agents, 14: 327-335.

Yu WL, Cheng HS, Lin HC, Peng CT, Tsai CH (2000). Outbreak investigation of nosocomial Enterobacter cloacae bacteraemia in a neonatal intensive care unit. Scandinavian J. Infect. Dis., 32: 293298 